\title{
Hacia una reinterpretación del artículo VI del Título Preliminar del Código Civil: en la búsqueda de los parámetros del "interés para obrar"(*)
}

\author{
Towards a reinterpretation of article VI of the Preliminary Title of the Civil \\ Code: in search of the parameters of the "standing to sue"
}

\author{
Eugenia Ariano Deho(**) \\ Pontificia Universidad Católica del Perú (Lima, Perú)
}

\begin{abstract}
Resumen: El presente trabajo analiza el artículo VI del Título Preliminar del Código Civil a los efectos de determinar su actual utilidad. Para ello se remonta a los orígenes y sentido de la máxima francesa "el interés es la medida de las acciones", su recepción en el Código Procesal italiano de 1865 y las evoluciones conceptuales sucesivas, hasta llegar a sostener que el artículo $\mathrm{VI}$ analizado contiene los parámetros necesarios (utilidad legítima, económica o moral) para establecer la existencia de lo que el Código Procesal Civil llama "interés para obrar", esto es, si lo demandado (o una defensa de fondo) tiene aptitud para recibir una decisión de fondo.
\end{abstract}

Palabras Clave: Interés para obrar - Interés legítimo - Interés económico - Interés moral - Demanda judicial - Proceso civil

\begin{abstract}
This paper analyses Article VI of the Preliminary Title of the Civil Code for the purpose of determining its current usefulness. For this purpose it goes back to the origins and sense of the French maxim "interest is the measure of actions", its reception in the Italian Procedural Code of 1865 and successive conceptual developments, going so far as to argue that article VI analyzed contains the parameters (legitimate, economic or moral usefulness) needed to establish the existence of what the Civil Procedural Code calls "interés para obrar", that is, if the requested (or a substantive defense) is appropriate to receive a substantive decision.
\end{abstract}

Keywords: Standing to sue - Legitimate interest - Economic interest - Moral interest Lawsuit - Civil proceedings

${ }^{*}$ *) Nota del editor: Este artículo fue recibido el 8 de febrero de 2020 y su publicación fue aprobada el 14 de mayo de 2020.

${ }^{* *}$ Profesora de Derecho Procesal Civil en la Pontificia Universidad Católica del Perú, en la Universidad Nacional de San Marcos y en la Universidad de Lima. Magíster en Derecho Procesal por la Pontificia Universidad Católica del Perú. Contacto: eariano@pucp. edu.pe 


\section{Introducción}

El artículo VI del Título Preliminar de nuestro Código Civil(1) establece que "[para] ejercitar o contestar una acción es necesario tener legítimo interés económico o moral. El interés moral autoriza la acción sólo cuando se refiere directamente al agente o a su familia, salvo disposición expresa de la ley", en razón de la vaguedad y oscuridad de sus términos, ha suscitado siempre muchas incertidumbres entre quienes se han lanzado a interpretarlo, intérpretes que, en particular desde el 28 de julio de 1993 (esto es, desde la entrada en vigencia del Código Procesal Civil), no le han reservado sino críticas, considerándolo, en sustancia, "una norma defectuosa y prescindible en nuestro sistema jurídico" (Monroy Gálvez, 1994a, p. 47).

De algo, sin embargo, se tiene la certeza: que el artículo VI constituye la transcripción del equivalente artículo IV del Código de 1936, artículo que - como ya ha sido reiteradamente evidenciado (Monroy Gálvez, 1994a, p. 37; Espinoza Espinoza, 2015 , p. 387) - a su vez, no era sino la versión "peruanizada" del artículo 76 del Código Civil brasilero de 1916: "Para propor, ou contestar uma ação, é necessário ter legitimo interesse econômico, ou moral. Parágrafo único. O interesse moral só autoriza a ação quando toque diretamente ao autor, ou á sua familia"(2). Ergo, estamos ante una disposición - como casi todo en nuestro ordenamiento jurídico - "importada", con todas las consecuencias negativas que suelen presentarse cuando, sin saber bien cuál sea su ratio, se trasplantan disposiciones de un ordenamiento a otro.

El presente trabajo pretende aproximarse al contenido del artículo $\mathrm{VI}$, a fin de verificar si realmente es un dispositivo superfluo o más bien conserva alguna utilidad en nuestro ordenamiento jurídico. Para ello, se buscará responder fundamentalmente a dos interrogantes: ¿qué quiere decir el artículo VI cuando señala que para "accionar"(3) (o contestar) hay que tener "legítimo interés, económico o moral"? y ¿es el "interés" del artículo VI el mismo o un distinto "interés" del que discurre el Código Procesal Civil bajo la locución "interés para obrar"?

Hay que aclarar que la investigación emprendida para dar respuesta a las indicadas interrogantes, y de la que se da cuenta en las líneas que siguen, se ha realizado sin sesgos o ideas preconcebidas, esto es, con toda apertura intelectual frente a un tema como el del "interés para obrar" (rectius, por las razones que se dirán, "interés en accionar") que a quien escribe siempre le ha suscitado dudas y perplejidades por lo que desde hace mucho tiempo se encontraba entre aquellos "pendientes" de aclarar. Juzgue el lector, si la finalidad se ha logrado.

\section{En la búsqueda del eslabón perdido: a) La máxima "l'intérêt est la mesure des actions"}

Para dar respuesta a la primera interrogante resulta inevitable dar una mirada al pasado, pero no respecto de la fuente inmediata de nuestro artículo $\mathrm{VI}^{(4)}$, sino ir algo más atrás: al origen y sentido de un viejo "axioma forense"(5) (Mancini en Mancini, Pisanelli y Scialoja, 1855, p. 77), un "principio general" (Mancini en Mancini, Pisanelli y Scialoja, 1855, p. 78), del cual el artículo 76 del CC brasilero no era sino su eco: l'intérêt est la mesure des actions (y sus variantes pas d'intérêt pas d'action; point d'intérêt, point d'action).

(1) En lo sucesivo el artículo VI del Título Preliminar del Código Civil será indicado solo como artículo VI.

(2) La disposición fue mantenida en el artículo 2 del Codigo de processo civil brasileño de 1939 ("Para propor ou contestar ação é necessário legítimo interesse, econômico ou moral") y luego "reducida" en el artículo 3 del Código de 1973 ("Para propor ou contestar ação é necessário ter interesse e legitimidade"). El artículo 17 del Codigo de processo civil de 2015 ha cambiado la redacción y establece que "Para postular em juízo é necessário ter interesse e legitimidade". Naturalmente, el Código Civil brasileño de 2002 ya no establece nada al respecto.

(3) Digo "accionar" (y no simplemente "actuar" o, peor, "obrar") porque "ejercitar una acción" es "accionar". Hay que notar que el artículo VI no dice, como dice Monroy Gálvez (1994a, p. 45) "iniciar una acción", sino "ejercitar una acción", por lo que buena parte de la crítica que se realiza en el trabajo a la redacción del artículo se desmorona. Sobre como deba entenderse el "ejercitar una acción", véase nota 37.

(4) Como se limitó a hacer "en atención a la brevedad del presente trabajo", Monroy Gálvez (1994a, p. 39-41), pese a decirnos que para hallar los antecedentes del artículo VI se podría remontar "a normas del siglo pasado [se refiere al S. XIX], las que, aún [sic] cuando fuese indiciariamente, desarrollan la temática contenida en la norma en estudio".

(5) Con ese mismo calificativo aparece en la Exposición de motivos del proyecto del CPC italiano de 1865 (obra de Giuseppe Pisanelli, coautor del Commentario del Codice di Procedura Civile per gli Stati Sardi) al justificar la presencia del artículo 36 (del que se dirá luego en el texto). Véase en Picardi y Giuliani (2004, p. 21). 
El adagio l'intérêt est la mesure des actions es muy anterior a la codificación napoleónica ${ }^{(6)} y$, como indicio de su antigüedad, estuvo a punto de positivizarse a instancia de la Corte de Casación francesa, quien propuso insertar en el Título Preliminar del Code de procédure civile napoleónico la fórmula: "el interés es la medida de las acciones; quien no tiene interés no es admisible en accionar" (Mancini en Mancini, Pisanelli y Scialoja, 1855 , p. 78$)^{(7)}$. La fórmula no fue aceptada ${ }^{(8)}$, pero ello no impidió a la jurisprudencia su aplicación "reconociéndole su autoridad e imperio" (Mancini en Mancini, Pisanelli y Scialoja, 1855, p. 78).

Estamos pues ante una "regla pretoriana" (Labbée, 1995, p. $42)^{(9)}$, que, en sus orígenes, tendía a individualizar "un criterio de claridad y de orden, un principio de razón, que permitiera depurar el proceso de todas las cuestiones que, ya prima facie, se presentaban del todo irrelevantes porque puramente ociosas, y así meramente abstractas, o inútilmente vejatorias" (Marinelli, 2005, p. 24-25): "una persona -decía Garsonnetno tiene el derecho de levantar cuestionamientos que no le importan y ocupar a los jueces con cuestiones que le son indiferentes" (cita en Marinelli, 2005, p. 25).

"Dado que el objeto de la acción, decía Adolphe Chauveau en sus anotaciones a Carré (1846, XXXVI-XXXVII), es constreñir a la persona contra la que está dirigida al cumplimiento de sus obligaciones, de ello se deduce que no puede intentarse ninguna, si no se tiene un interés particular y legítimo. Una demanda que tendería a perjudicar al demandado, sin aportar ningún beneficio legal al demandante, infaliblemente se rechazaría. De allí máxima: El interés es la medida de las acciones"(10).

Por tanto, el interés al que aludía la máxima no era, por usar la fórmula de Jhering (que ni había nacido cuando ella surgió), la existencia de un "interés jurídicamente tutelado" (esto es, un derecho subjetivo [como especuló Leon Barandiarán (1985, p. 28) $\left.{ }^{(11)}\right]$ ), sino el interés entendido como el "beneficio", como la "ventaja", como la "utilidad" que, de estimarse la demanda, se le produciría al demandante ${ }^{(12)}$; caso contrario, la demanda sería declarada inadmisible (irrecevable) por el juez; esto es, "sin examinar si el derecho sobre el que está establecida está bien o mal fundado" (Chauveau en Carré, 1846, p. XXXVI). Es decir, el intérêt à agir era concebido cual condition, junto con la qualité y la capacité, para hacer las "acciones" admisibles ante los jueces ("conditions requises pour rendre les actions recevables en justice": Poncet, 1835, p. 64) y cuya ausencia les autorizaba a no entrar al fondo; esto es, decidir si la demanda era fundada o no.

(6) Según Consolo (2015, p. 574) los adagios responden a un modelo de "quieta racionalidad jansenista". En esa línea, señala Marinelli (2005, p. 23-24): "tales aforismos no podían sino nacer y fermentar en aquella peculiar y singularísima atmósfera cultural y jusfilosófica de inspiración cartesiana y jansenista -que caracteriza ciertos ambientes de 'artesanía intelectual' de la Francia en los tiempos antecedentes a las grandes codificaciones napoleónicas- fuertemente marcada por la aspiración a la búsqueda de claridad y del orden también en el ámbito jurídico. Las tesis de Descartes habían hecho emerger, también en el contexto jurídico, la preocupación y la necesidad de aclarar el propio pensamiento, las propias acciones; del método jansenista se desprendía, en cambio, la tensión de todas las ciencias (morales y espirituales) hacia el orden".

(7) Mancini transcribe en italiano la fórmula propuesta del "axioma": "L'interesse è la misura delle azioni; chi è senza interesse non è ricevibile ad agire".

(8) Conforme lo precisa Roger Perrot (1975, p. 238), el pragmatismo que inspiró a los redactores (todos jueces y abogados) del Código procesal civil napoleónico de 1806 los llevó a eliminar todo aquello que podía parecer una construcción doctrinal: "la de la acción es, a propósito, un ejemplo típico. Al momento de la elaboración del código de procedimiento de 1806 la Corte de Casación había hecho observar que habría sido oportuno que varios artículos del código se consagraran a los principios generales sobre la acción. La sección del Tribunado (que era una asamblea legislativa) respondió que se trataba de cuestiones puramente doctrinales que no encontraban lugar en un código".

(9) También Enrico Allorio, en su famoso ensayo crítico de la tesis de Schönke sobre la "necesidad de tutela jurídica" (Rechtsschutzbedürfnis), encuentra en la noción de interesse ad agire latina una huella no doctrinal (como en Alemania) sino "curialesca" (1954, p. 89). Piero Calamandrei, por su lado, atribuye los aforismos franceses al uso de "los prácticos" (1962, p. 268).

(10) 'Le but de l'action étant de contraindre celui contre lequel elle est dirigée à l'accomplissement de ses obligations, il s'ensuit qu'on ne peut en former aucune, si l'on n'a un intérêt particulier et légitime. Una demande qui tendrait qu'à nuire au défendeur, sans apporter aucun profit légal au demandeur, serait done infailliblement rejetée ; de là cette maxime : L'intérêt est la mesure des actions". En la versión napolitana de la obra de Carré (1841, p. 24) el pasaje aparece así: “Essendo lo scopo dell'azione costringere all'adempimento delle sue obbligazioni colui contra cui l'azione è diretta, ne siegue [sic] non potersene alguna intentare, senza che vi sia un'interesse particolare e legitimo [sic]. Sarebbe dunque immancabilmente rigettata quella dimanda [sic] che senza recare alcun vantaggio all'attore, nuocesse al convenuto: da ciò la massima, l'interesse è la misura delle azioni".

(11) En efecto, el recordado maestro decía que el artículo VI "está tratando exclusivamente del derecho subjetivo".

(12) Aquel interés que, luego, se le llamará "interés secundario" (frente al "interés primario" o sea, el tutelado por la norma) en los enredos teórico-dogmáticos de las diversas teorías de la acción elaboradas primero en Alemania y, luego, en Italia entre fines del Siglo XIX y la primera mitad del siglo XX. Sobre estas teorías, es siempre útil leer (y releer) a Orestano (1959, p. 785-829). 
Que tal fuera la "idea" que nutría la máxima francesa, da fe el napolitano Pasquale Stanislao Mancini, quien en 1855 , en el volumen II del "monumental"(13) Commentario del Codice di Procedura Civile per gli Stati Sardi, incluía el interés entre "las condiciones para la admisibilidad de la acción misma" (en Mancini, Pisanelli y Scialoja, 1855, p. 67)(14): "El actor debe tener un interés para instituir la acción y para que sea estimada. Si pudiera demostrarse que la acción planteada fuera incapaz de producirle algún resultado para él ventajoso, y servir a una finalidad útil; la justicia le negaría el beneficio de su protección, no estando constituida para dar ociosas y académicas opiniones" [cursivas agregadas] (en Mancini, Pisanelli y Scialoja, 1855, p.77) ${ }^{(15)}$.

Pero según la elaboración jurisprudencial francesa, pero, también, la belga y la "italiana"(16), de la que nos da cuenta Mancini, ese interés necesario para hacer admisible la "acción" no era "cualquier" interés (cualquier beneficio-ventaja-utilidad), sino que debía ser un interés: (i) directo (esto es, del "individuo como privado y no como ciudadano y miembro de la sociedad": (1855, p. 80) no solo "pecuniario" sino también "de honor" (individual ${ }^{(17)}$ o familiar $\left.{ }^{(18)}\right)(1855, \mathrm{p}$. 81)(19); (ii) legítimo (esto es que "no tiene la finalidad de exceder la medida de sus propios derechos e invadir la esfera de los derechos ajenos, infringir las prohibiciones de la ley o de la moral, o de ejercitar una libertad de acción o una prerrogativa que no puede ser útil sino para crear el peligro de un abuso, o a hacer imposible el develamiento y la represión": Mancini en Mancini, Pisanelli y Scialoja, 1855, p. 93); y (iii) actual ("debe concernir la preservación de un derecho o legítima facultad que ya existe": Mancini en Mancini, Pisanelli y Scialoja, 1855, p. 95)(20).

(13) El calificativo es de Cipriani (1991, p. 14). Realmente el Commentario es monumental y se haría bien en darle, de vez en cuando, una ojeada (en particular porque se le puede encontrar on line).

(14) La otra "condición" era la "calidad" (qualità), en la cual Mancini incluía la titularidad del derecho, su disponibilidad y la capacidad para estar en juicio por parte del demandante. La "calidad", como condición para "instituir (es decir, ejercitar) la acción", cincuenta años después, será rebautizada por Chiovenda como legittimazione ad agire, concebida como una de las tres "condiciones generales de la sentencia positiva que estima la demanda" (las otras dos eran la "esistenza del diritto" y el "interesse ad agire" [véase en español, Chiovenda (1924, p. 195 y ss; 1954, p. 208 y ss.)]. Hay que precisar que Casais y Santaló en la traducción de los Principii tradujo la legitimazione ad agire chiovendiana como "legitimación para obrar", mientras que para el interesse ad agire, cambió de preposición, y la tradujo como "interés en obrar". Gómez Orbaneja hizo lo propio en las Instituciones. Tengo mis dudas sobre ambas traducciones, a comenzar por traducir "agire" por "obrar" (si el "agire" es la acción de ejercitar la acción, debería ser "accionar") y, luego, cuál de las preposiciones (si "para" o "en") sea la más correcta. Si entendemos por interés "utilidad", el "para" debe descartarse porque no tendría sentido, por lo que, parece que Casais y Santaló al decidir traducir "interesse ad agire" por "interés en obrar" encontró la preposición correcta.

(15) Un poco más adelante Mancini agregaba: “La máxima, de cuya aplicación se trata, no debe producir otra cosa más que el alejamiento de la arena judicial de aquél que en ella no tenga ningún real y legítimo interés que defender, y que sin ninguna útil finalidad quisiera envolver a la sociedad del juicio de cuestiones más o menos ociosas, o privadas de valor jurídico" (en Mancini, Pisanelli y Scialoja 1855, p. 81).

(16) Cabe tener en cuenta que Italia, como Estado unitario, solo existe desde 1861 (para ser precisos, desde el 17 de marzo de 1861), por lo que la jurisprudencia es la de los diversos estados pre-unitarios de la península.

(17) Como respecto de la demanda planteada por un comerciante en la que pretendía que se declarara que él no había cedido por entero un crédito de un deudor caído en estado de cesación de pagos, circunstancia que el cesionario sabía, sino solo aquella fracción a la que había quedado reducido el crédito como consecuencia de un concordato ocurrido entre todos los acreedores. El interés del demandante consistía en que se excluyera que él como cedente hubiera cometido "una falta de delicadeza contraria a la lealtad del comercio" (ceder un crédito cuando el cedido estaba en estado de insolvencia). La Corte de Casación francesa, por sentencia de agosto de 1841, consideró que el demandante tenía "un real interés, y por tanto una acción planteable" (Mancini en Mancini, Pisanelli y Scialoja, 1855, p. 81).

(18) Por lo general el interés "de familia" entraba en juego en casos de usurpación de nombre (rectius, del apellido familiar), pero no solo. Tal fue el caso visto por la Corte de Grenoble (16 de mayo de 1842) en el que los herederos legítimos, más no legitimarios, pretendían que se constriñera al heredero universal testamentario a cumplir los cargos de la institución en el interés de la familia, cargo consistente especialmente en la erección de un monumento funerario del testador y en hacer litografiar los dibujos de una colección arqueológica de la antigüedad recogida por el causante durante su vida. La Corte francesa, en tal caso, reconoció la existencia de un interés "de familia" en los demandantes que hacía admisible su "acción" (Mancini en Mancini, Pisanelli y Scialoja, 1855, p. 83).

(19) Precisaba Mancini: "el honor no es solamente la vida y el orgullo del alma, sino de ordinario es fuente además de crédito, de fortuna y de preciosas utilidades valorables. Cualquier interés privado susceptible de garantías civiles, y al cual en el concepto común se atribuye seriedad e importancia para una ordenada convivencia, merece sin duda la protección de la ley y de la pública potestad" (en Mancini, Pisanelli y Scialoja, 1855, p. 81).

(20) La actualidad del interés, debía medirse en función de lo demandado. Así, "un derecho subordinado a alguna condición crea, sin embargo, un interés actual a conservarlo y a custodiarlo ileso, porque la condición suspende el ejercicio del derecho, pero no impide su actual nacimiento. También la amenaza de un daño eventual puede devenir la base legítima de una acción, por cuanto esta amenaza constituye por sí misma una molestia actual de la pacífica y segura posesión del actor" (Mancini en Mancini, Pisanelli y Scialoja, 1855, p. 96). 


\section{Sigue b) El artículo 36 del Codice di procedura civile italiano de 1865}

Y así llegamos al Codice di procedura civile (unitario) italiano de 1865 que "congela" (Nasi, 1972, p. 32) la máxima en su artículo 36 , con la siguiente fórmula: "Para plantear una demanda en juicio, o para contradecirla, es necesario tener interés"(21). La neo disposición fue explicada así por Giuseppe Pisanelli: "Es conocido el axioma, que el interés es la medida de las acciones. La doctrina y la jurisprudencia lo han siempre considerado; corresponde a las mismas regular su aplicación: a la ley le basta enunciarlo" [cursiva agregada] (Picardi y Giuliani, 2004, p. 21) (22).

Y justamente la primera doctrina "procedurista" italiana ${ }^{(23)}$ asumirá la empírica ${ }^{(24)}$ concepción del interesse ad agire cual "utilidad"(25). Y así decía Luigi Borsari que ese "interés", ya exigido por el artículo 36 de su CPC, esto es, por una ley, existía "cuando la declaración del derecho, que para nosotros se pide a la autoridad judicial, puede ser útil a nuestra persona o a nuestro patrimonio", cual "condición" para alegar el derecho y "para ser oídos cuando se propone de demostrarlo" $\left(1878\right.$, p. 81-82) ${ }^{(26)}$, interés que podía ser, agregaba Giuseppe Saredo -siguiendo a pie juntillas a Mancini-, tanto "pecuniario como moral", pues "un interés de honor es tan legítimo como aquél que concierne a una suma de dinero" [cursivas del autor] (Saredo, 1873, p. 197).
Esta concepción del interesse ad agire -tan lineal, tan comprensible, tan sensatamente francesa- perdurará en la doctrina y en jurisprudencia italiana durante toda la segunda mitad del Siglo XIX, hasta que a inicios del Siglo $X X$ se producirá el blackout: la entrada en escena de Giuseppe Chiovenda, para quien el interesse ad agire ya no es más esa utilidad requerida para hacer admisible la "acción" (y que pueda emitirse una decisión de fondo), sino, siguiendo al alemán Adolf Wach(27), una condición "para la actuación de la voluntad de la ley", es decir, una de "las condiciones necesarias para obtener una resolución FAVORABLE" [mayúsculas del autor] (Chiovenda, 1924, p. 129), que "no consiste únicamente en conseguir el bien garantizado por la ley (esto constituye el contenido del derecho) sino el interés en conseguirlo mediante los órganos jurisdiccionales" [cursiva del autor] (Chiovenda, 1924, p. 199) (28). "Por regla general -sentenciaba "científicamente" Chiovenda (1954, p. 212)- puede decirse que el interés en obrar consiste en esto: que, sin la intervención de los órganos

(21) "Per proporre una domanda in giudizio, o per contraddire alla medesima, è necessario avervi interesse". El artículo 36 del CPC de 1865, pasó idéntico al artículo 100 CPC italiano de 1940.

(22) Nótese el atemporal "siempre" empleado por Pisanelli para referirse a la exigencia del interés.

(23) La de aquellos a los que se les suele llamar "los prechiovendianos", por lo general olvidados y cuando recordados (aún en tiempos recientes), denostados, en cuanto representarían "el reino opaco y somnoliento de la exégesis [...], es decir de una ley que absorbe y agota la realidad, de una realidad reducida a escenario de modelos abstractos y por tanto encerrable en un texto, de un jurista apagado y débil porque no involucrado dentro de las fuerzas productivas del ordenamiento y por tanto psicológicamente pasivo": así Grossi (2000, p. 62-63). En sentido diametralmente distinto, reivindicando a los viejos "proceduristi", véase el inigualable Cipriani (1991, p. 13-20).

(24) "Empírica" en cuanto extraída de la experiencia judicial, no del "cielo de los conceptos".

(25) Lo decía Alfredo Rocco, a inicios del Siglo XX, ya desde el cielo de los conceptos: "Según la doctrina dominante, el interés en accionar [interesse ad agire] es la utilidad que al titular del derecho subjetivo deriva del provocar a su favor la tutela jurisdiccional" (A. Rocco, 1906, p. 103). Curiosamente Ugo Rocco, en 1957, con las mismas exactas palabras que su hermano escribiera cincuenta años antes, seguirá repitiendo aquello de que "Según la doctrina dominante, el interés en accionar sería la utilidad que el titular de un derecho subjetivo deriva de la tutela jurisdiccional" [cursivas del autor] (Rocco, 1957, p. 322). Evidentemente, si a inicios del Siglo XX, como se ha visto en el texto, era la opinión dominante, ya no era así a nivel de la doctrina procesal italiana en los años cincuenta del Siglo pasado cuando ve la luz el Trattato de Ugo Rocco.

(26) Borsari (1878, p. 82) reconocía que aquella del interés era una "noción vaga e indeterminada", pero que había que mirarla "bajo un aspecto no absoluto, sino relativo; y el interés tiene siempre algo de específico cuando se relaciona al objeto de la cuestión. Dos cualidades que en él deben concurrir, moderan la extensión del concepto. El interés debe ser directo y legítimo".

(27) Chiovenda, en línea con Adolf Wach, abrazó una concepción de la acción "concreta", esto es, como derecho a una sentencia favorable: la Rechtsschutzanspruch ("pretensión de tutela jurídica") de los alemanes de fines del siglo XIX, luego abandonada en el Siglo XX.

(28) En teórica alemana de la acción como Rechtsschutzanspruch uno de sus presupuestos era el Rechtsschutzbedürfnis ("necesidad de tutela jurídica"), es decir, quien carecía de Rechtsschutzbedürfnis no tenía Rechtsschutzanspruch. Al decir Chiovenda que el interesse ad agire consiste en obtener el bien garantizado por la ley "mediante los órganos jurisdiccionales" reflejaba la concepción de la "necesidad de tutela jurídica" germana. Sobre la evolución del "concepto" de Rechtsschutzbedürfnis en la doctrina alemana y su particularmente perversa aplicación judicial durante el nazismo para negarle a los judíos la "necesidad de tutela jurídica”, véase la documentada monografía de Marinelli (2005, p. 31 y sucesivas). 
jurisdiccionales, el actor sufriría un daño injusto"(29). De esta "noción" (si así puede llamarse) "partirán prácticamente todas las otras" (Satta, 1954, p. 170): la de Betti (1932, p. 230)(30), la de Calamandrei (1962, p. 273) ${ }^{(31)}$, la de Zanzucchi (1947, p. $177)^{(32)}$, en parte la de Attardi (1962, p. 841) ${ }^{(33)}$ y la de Liebman $(2007 \text {, p. 140) })^{(34)}$, etc.

\section{El artículo VI: un innocuo eco de las voces del pasado}

Ciertamente, el "inconsistente"(35) concepto del interesse ad agire chiovendiano ( $\mathrm{y}$ sus derivados), poco o nada tiene que ver con nuestro artículo VI, pues tal disposición al haber recogido (por intermedio del artículo IV del T.P. del CC de 1936) la fórmula del artículo 76 del CC brasilero de 1916, no constituye sino un eco de las voces pronunciadas en la (culturalmente) lejana Francia del pasado, las que con espíritu estrictamente práctico querían, con la fórmula l'intérêt est la mesure des actions, marcar un límite "más allá del cual no le estaba permitido al actor empeñar a los órganos jurisdiccionales con cuestiones ociosas o del todo irrelevantes degradando así al juez al papel de mero consultor de la parte" (Marinelli, 2005, p. 25).

Pero estas voces del pasado al ser recogidas, primero por los brasileños $y$, luego, por nosotros, de la "fórmula" del artículo 36 del CPC italiano ("enriquecida" por aquellas calidades que unánimemente la vieja doctrina

(29) Sin embargo, la transcrita en el texto es la "noción general", porque según Chiovenda (1954, p. 199) el interés "varía según la manera de actuar la ley que se invoca (sentencia de condena o de declaración, medidas cautelares preventivas, etc.)". Así tratándose de sentencias de condena se requeriría de la lesión del derecho, esto es, "un estado de hecho contrario a derecho; que la expectativa del actor se encuentre en la situación de no satisfacción" [cursivas del autor] (1954, p. 217); tratándose de sentencias constitutivas, en cambio, "el interés en obrar, como condición específica de la acción junto a la existencia del derecho, no tiene aquí lugar; en efecto, el mismo derecho potestativo al cambio del estado jurídico mediante declaración del juez, no puede satisfacerse sino mediante sentencia del juez" [cursivas del autor] (1954, p. 234); tratándose de sentencias meramente declarativas "el interés en obrar se da por una situación de hecho tal que el actor, sin la declaración judicial de la voluntad concreta de la ley, sufriría un daño injusto, de manera que la declaración judicial se presenta como el medio necesario para evitar ese daño" (1954, p. 263; 1993, p. 68).

(30) Según Emilio Betti el interesse ad agire (o a contraddire para el demandado) "nace de un estado de hecho contrario al derecho, que forma objeto de valoración por parte de la ley procesal: estado de incertidumbre en la apreciación del quid iuris o de inobservancia del vínculo jurídico, el cual hace sentir prácticamente la necesidad de una intervención de los órganos jurisdiccionales para eliminar la incertidumbre o para superar la resistencia opuesta o amenazada al ejercicio del derecho" [cursivas del autor].

(31) Piero Calamandrei, de plano, lo llamó "interés procesal", el cual existiría cuando "la finalidad que el solicitante se propone alcanzar mediante la acción no puede (o no puede ya) ser alcanzada, sino mediante la providencia del juez; cuando la situación jurídica existente antes del proceso es tal que el recurso a la autoridad judicial se presenta como necesario" [cursiva del autor] (Calamandrei, 1962, p. 273, ).

(32) Marco Tullio Zanzucchi, pese a que consideraba que "la calidad o legitimación en accionar y el interés en accionar, propiamente son solo requisitos para que el juez, verificado el concurso de los 'presupuestos procesales', pueda pasar a tratar el fondo" (y no, como sostenía Chiovenda y sobre sus huellas Calamandrei, para emitir una sentencia favorable), señalaba chiovendianamente, que el interés en accionar nacía "de un 'estado de hecho contrario al derecho', que no puede ser removido sin la intervención de los órganos jurisdiccionales, y se sustancia en el daño que a la parte se le produciría si estos no interpusieran su actividad” (Zanzucchi, 1947, p. 177).

(33) Aldo Attardi (quien abrazó una concepción abstracta de la acción) compartía con la doctrina "tradicional" (que para Attardi era la chiovendiana) el que el artículo $100 \mathrm{CPC}$ italiano expresara "la exigencia de que, además de la existencia (o la afirmación de la existencia) del derecho subjetivo hecho valer, subsista un estado de hecho lesivo (en sentido lato) del derecho mismo, vale decir, una situación que afecta y disminuye el valor de una situación subjetiva", discrepando, sin embargo, en su alcance: "no en los procesos de condena y de declaración constitutiva, y tampoco en el de ejecución, sino solo en los procesos de mera declaración y cautelar" (Attardi, 1962, p. 841).

(34) Enrico Tullio Liebman (que, en cuanto sostenedor de la teoría "semi-abstracta" de la acción, concebía las "condiciones de la acción" como exigencias para que el juez pueda pronunciarse sobre el fondo), señalaba que en atención a que "el derecho de accionar está dado para la tutela de un derecho o un interés legítimo, está claro que solo le corresponde cuando hay necesidad de la tutela, es decir cuando el derecho o el interés legítimo no ha sido satisfecho cuando debía serlo, o cuando ha sido cuestionado, ha devenido incierto y por tanto gravemente amenazado. Así viene individualizada la situación objetiva que justifica el planteamiento de la demanda: es aquella que se llama interés en accionar [interesse ad agire]" [cursivas del autor] (2007, p. 147). La de Liebman es la que podemos llamar noción "estándar" de la doctrina italiana actual, en la que el interesse ad agire es entendido cual "relación de utilidad que corre entre la lesión de un derecho, que ha sido afirmada, y la medida [provvedimento] de tutela jurisdiccional que es demandada" [cursivas del autor] (2007, p. 146), pero la matriz sigue siendo chiovendiana. Liebman, igualmente, sentó las bases del trinomio "utilidad-necesidad-idoneidad" (utilidade-necessidade-adequação) de la medida jurisdiccional demandada como metro del interesse de agir que es tan común en la doctrina brasilera (véase, por todos, Cintra, Pellegrini y Dinamarco, 2003, p. 259).

(35) La expresión es de Satta (1954, p. 170): "decir que el interés está dado por el que el no ejercicio de la jurisdicción produce un daño, equivale a decir que el interés en accionar es el interés en accionar". 
requería del intérêt à agir: el ser legítimo, directo, económico o moral( $\left.{ }^{(36)}\right)$, resultó una recepción "a medias", porque no se estableció la consecuencia: ¿quid si el que "ejercita una acción" (léase, el que demanda ${ }^{(37)}$ ) no tiene ese interés (legítimo, directo, económico o moral) que le "autoriza" la acción?

Como hemos visto, la doctrina y la jurisprudencia francesa consideraban (y lo siguen considerando) al intérêt à agir como una "condición" para hacer la "acción" recevable (admisible), esto es, para que se pueda emitir una decisión de fondo(38) (39). Nada de ello aparece en nuestro artículo VI (como no aparecía en sus precedentes "textuales"), por lo que la disposición, como "norma", está incompleta: prescribe la necesidad del "interés", pero no establece la consecuencia de su ausencia.

Sin embargo, si se tiene presente cuáles son sus verdaderos antecedentes no debería ser difícil (ni forzado) extraer la norma encerrada en el texto: allí donde dice "Para ejercitar [...] una acción es necesario tener [...] interés económico o moral", debe entenderse que para que una demanda sea admisible lo concretamente demandado debe serle útil al demandante, esto es, que, en la hipótesis de ser estimada, debería procurarle una ventaja en su esfera jurídica sustancial.
Si esto es así, como -tras mil tormentosestoy convencida que es: ¿qué podía significar en 1984 (y antes en 1936) el que una demanda planteada por un sujeto carente de "interés" era inadmisible? Pues muy poco. $Y$ ello porque si el artículo VI deriva (inconscientemente) de la tradición procesal francesa, el ordenamiento procesal vigente en la época (el Código de Procedimientos Civiles de 1912), lo era de la tradición procesal castellana, que ni por asomo se planteaba la cuestión de que la "acción" tuviera "condiciones" que pudieran determinar la "inadmisibilidad" de la demanda, en los términos que ello era entendido por los franceses.

De hecho, en aquel entonces, si algún juez "docto" hubiera entendido lo que se encerraba en nuestro art. VI (y antes en el art. IV del CC de 1936), a lo más, en la sentencia (es decir, al final del "juicio"), de apreciar una "carencia de interés" en el demandante, hubiera declarado "inadmisible" (o, sus equivalentes: "improcedente" o "no ha lugar a") la demanda.

(36) También por los civilistas italianos del S. XIX. Así Emmanuele Gianturco (1921, p. 345) decía: “Solo puede experimentar una acción quien tenga interés jurídico en la reintegración o al reconocimiento del derecho (artículo $36 \mathrm{CPC}$ ). [...] El interés puede ser material o moral: el interés material da siempre derecho a experimentar la acción; el moral, en cambio, solo cuando toca directamente al actor o a su familia". Es evidente la semejanza entre la fórmula del artículo 76 del CC brasileño de 1916 y el pasaje de Gianturco.

(37) Entre las tantas críticas efectuadas a la redacción del artículo VI está el haber hecho referencia a la "acción" y no, en todo caso, a la "demanda". Nuevamente hay que acudir a la vieja doctrina. Así decía Carré (1841, p. 22): "Todo derecho que emerge de una ley positiva supone la facultad de reclamar el apoyo de la autoridad judicial, sea para obtener, conservar o readquirir el goce de este derecho, o bien para ser indemnizado por su privación. Tal facultad, en el significado más amplio de la palabra, se le dice acción [...]. Pero las leyes de procedimiento, sea civil o penal, miran la acción bajo otro aspecto, y la consideran como próxima a ser o que ya haya sido introducida en juicio; de tal manera que en el lenguaje práctico, la acción es el ejercicio de la facultad de reclamar nuestros derechos, o bien, en otros términos, cualquier demanda producida ante la autoridad judicial. Las palabras, pues, acción, demanda son perfectamente sinónimas; de manera que para expresar el derecho que tiene un individuo de hacer una demanda se usa la palabra acción; de la misma manera se dice que intentada una acción cuando se quiere denotar el haberse formulada una demanda". Ergo, para los "antiguos" "ejercitar una acción" significaba "interponer una demanda" (tal como Pisanelli lo colocó en el artículo 36 CPC italiano de 1865). Que también se entendiera así en nuestra familia jurídica, lo tenía muy claro José de Vicente y Caravantes (1856, p. 431): "La demanda ó libelo no es otra cosa que el ejercicio de una acción" [cursivas del autor]. Entre nosotros, Calle (1912, p. 156): "Demanda [...] es [...] el ejercicio de la acción".

(38) El (ya no Nouveau) Code de procédure civile francés, entrado en vigencia el 1 de enero de 1976, ha "definido" a la acción (artículo $30:$ "L'action est le droit, pour l'auteur d'une prétention, d'être entendu sur le fond de celle-ci afin que le juge la dise bien ou mal fondée. Pour l'adversaire, l'action est le droit de discuter le bien-fondé de cette prétention" ["La acción es el derecho, para el autor de una pretensión, a ser oído sobre el fondo de ella para que el juez decida si está bien o mal fundada. Para el adversario, la acción es el derecho de discutir si la pretensión está bien fundada"]) y sus condiciones de existencia (artículo 31: "L'action est ouverte à tous ceux qui ont un intérêt légitime au succès ou au rejet d'une prétention, sous réserve des cas dans lesquels la loi attribue le droit d'agir aux seules personnes qu'elle qualifie pour élever ou combattre une prétention, ou pour défendre un intérêt déterminé" ["La acción está abierta a todos aquellos que tienen un interés legítimo en el éxito o rechazo de una pretensión, salvo en los casos en los que la ley otorga el derecho de accionar a las únicas personas que ella califica para plantear o combatir una pretensión, o para defender un determinado interés"]). La noción de acción acogida el CPC francés corresponde a Henri Motulsky (1973, p. 85-100).

(39) El "interés legítimo" enunciado por el artículo 31 del CPC francés vigente (véase nota anterior) como condición de la "existencia" del derecho de acción, es apreciable de oficio (artículo 125) y su carencia puede ser opuesta, en cualquier estado del proceso, por la contraparte a través de un fin de non-recevoir (algo así como una "excepción de inadmisibilidad"). La fin de non-recevoir es así definida por el artículo 122: "Constitue une fin de non-recevoir tout moyen qui tend à faire déclarer l'adversaire irrecevable en sa demande, sans examen au fond, pour défaut de droit d'agir, tel le défaut de qualité, le défaut d'intérêt, la prescription, le délai préfix, la chose jugée" ["Constituye una fin de non-recevoir todo medio que tienda a que se declare inadmisible la demanda del adversario, sin examen de fondo, por ausencia del derecho de acción, como la falta de calidad, la falta de interés, la prescripción, la caducidad o la cosa juzgada"]. 
Hacia una reinterpretación del artículo VI del Título Preliminar del Código Civil: en la búsqueda de los parámetros del "interés para obrar"

Towards a reinterpretation of article VI of the Preliminary Title of the Civil Code: in search of the parameters of the "standing to sue"

Y ello porque el art. 307 del CPC de 1912(40), tras la presentación de la demanda, solo permitía al juez "devolverla" si es que no cumplía con los requisitos del art. 306 (que eran muy pocos ${ }^{(41)}$ ). Y tampoco el demandado habría podido plantear la "carencia de interés" del demandante como "excepción dilatoria" (esto es, como una cuestión de previo y especial pronunciamiento), porque la lista de "dilatorias" en el CPC de 1912 era "cerrada"(42) y no abierta (como lo era en el Código de Enjuiciamientos en materia civil de 1852, siguiendo la tradición del proceso común medieval(43)), por lo que solo habría podido, a lo más, deducir la carencia de interés del demandante al contestar la demanda ${ }^{(44)}$.

Por tanto, esos ecos de las voces del pasado que se recogieron en el texto de nuestro artículo VI, ni aun interpretándose a la luz de sus auténticas fuentes, habrían producido una decisión de "inadmisibilidad" de la demanda (esto es, no de fondo) in limine o en un momento anterior al de la sentencia conclusiva del "juicio". Ergo, el artículo VI, incluso bien interpretado era, desde el punto de vista de la dinámica procesal, bastante innocuo (aunque no intrascendente) ${ }^{(45)}$.

\section{El advenimiento del Código Procesal Civil de 1993 y el inciso 2 de su artículo 427}

Hay algo que (espero) esté ya claro: el artículo VI, como en efecto ha sido dicho (Monroy Gálvez, 1994a, p. 41), contiene una "norma procesal"(46). Que su "lugar" correcto sea el Título Preliminar del Código Civil puede ser discutible (tan discutible como la presencia del resto de sus disposiciones, que ya, en su mayoría, están en la Constitución de 1993), pero que es una norma procesal lo es ${ }^{(47)}$.

Ahora bien, la norma procesal, hay que reiterarlo, "encerrada" en el artículo VI es aquella que sanciona con la inadmisibilidad a la demanda planteada por quien no tiene "interés" -o sea, por quien no obtendría ninguna utilidad (o beneficio o ventaja: la palabra que se quiera)- de su estimación. Naturalmente, la "inadmisibilidad" aludida debe entenderse "a la francesa", esto es, cuando la demanda "no llena todas las condiciones de las cuales depende que se la examine en su fondo o contenido" (Loreto, 1970 , p. 41) $)^{(48)}$.

Y si esta "norma" era bastante innocua durante la vigencia del CPC de 1912, deja de serlo desde el 28 de julio de 1993, es decir, desde la entrada en vigencia del Código Procesal Civil, no solo y no tanto, porque el artículo IV del Título Preliminar de ese Código establece que "[el] proceso se promueve sólo a iniciativa de parte, la que invocará interés y legitimidad para obrar", dejando sobrentendido qué sea ese interés que "invoca" el demandante ${ }^{(49)}$, sino porque la

(40) Disponía el artículo 307 del Código de Procedimientos Civiles de 1912: "La demanda que carezca de alguna de estas formalidades [las del artículo 306] será devuelta, debiendo el juez precisar en la providencia el requisito que se ha omitido".

(41) Para la nostalgia, reproduzco el simple (frente al farragoso artículo 424 del Código de Procedimientos Civiles vigente) artículo 306 del Código de Procedimientos Civiles de 1912: "La demanda contendrá: $1^{\circ}$. La designación del juez ante quien se interpone; $2^{\circ}$. Los nombres del demandante y demandado; $3^{\circ}$. La determinación precisa de la materia que se demanda; $4^{\circ}$. Los fundamentos de hecho y de derecho que la apoyan".

(42) Véase el artículo 612 del Código de Procedimientos Civiles de 1912, que solo permitía el planteamiento de las siguientes excepciones como "dilatorias": incompetencia; pleito pendiente, falta de personería, inoficiosidad de la demanda; naturaleza de juicio, transacción y cosa juzgada. En 1977, por Decreto Ley №21773, se agregarán la prescripción y el pleito acabado. Ninguna de estas "dilatorias" podía albergar la alegación de la falta de interés en accionar del demandante.

(43) Véase los artículos. 619 (excepciones dilatorias) y 620 (excepciones perentorias) del Código de 1852. Ambos artículos indicaban un listado precedido de la frase "las más comunes son...". Ergo, la lista no era cerrada, sino abierta.

(44) Bajo el "nombre" de "excepción de falta de acción" (exceptio sine actione agit) o cualquier otro. En el sentido de que la excepción de "falta de acción" (carencia de legitimación, interés y posibilidad jurídica) no se podía deducir (en el derecho uruguayo, no muy distinto al nuestro) como excepción dilatoria sino en la contestación de la demanda y debía juzgarse en la sentencia, como paso previo al juicio de fondo, véase Véscovi (1972, p. 250-251). En el Código General del Proceso uruguayo de 1988, aparece ya como excepción "previa" en el inciso 9 del artículo 133.

(45) A comenzar por si una declaración de inadmisibilidad (o de improcedencia, o un "no ha lugar"), tenía o no la aptitud de devenir cosa juzgada, tema éste sobre el cual no me voy a detener porque requeriría de un (demasiado) largo discurso.

(46) También Giovanni Priori (2003, p. 54) considera que el artículo VI es "procesal", pero, en el entendido de que tal artículo "hace referencia a una institución típicamente procesal, cual es la legitimidad para obrar”. Excluye también que el artículo VI se refiera al "interés para obrar", Avendaño Valdez (2010, p. 64).

(47) Con todas sus consecuencias: in primis, que es parte de la lex fori, por lo que se aplica, aunque el fondo deba decidirse conforme a norma extranjera.

(48) Luis Loreto, eminente procesalista venezolano, como buen conocedor de la doctrina procesal, también la francesa, tenía muy claro el significado de "inadmisibilidad". Sobre la noción actual (que sigue siendo la misma de antaño) en el derecho francés de "recevabilité de la demande en justice" y su diferencia con el que sea "bien fondé", véase el siempre clarísimo Perrot (1995, p. 491-493). 
carencia "manifiesta" de "interés para obrar" fue colocada entre los supuestos en los que la demanda debe ${ }^{(50)}$ ser declarada "improcedente" (inc. 2 del artículo 427 CPC), pudiendo esta declaración ser adoptada, auténticamente, in limine, esto es no como cuestión a analizarse en la sentencia de manera previa al fondo, sino en sentido literal: "en el umbral", al inicio mismo, esto es, tras la presentación misma de la demanda ${ }^{(51)}$.

Y como los más excluyen que el "interés para obrar" del artículo IV del T.P. CPC sea el "legítimo interés" (económico o moral) de nuestro artículo $\mathrm{VI}$, resulta evidente que el CPC abrió una puerta peligrosa, pues cada intérprete, en base a "su" noción (extraída de algún texto a la mano)(52) de "interés para obrar", puede encontrar los casos más disparatados de carencia "manifiesta" de aquél ${ }^{(53)}$.

Sin embargo, pese a la contraria communis opinio, nuestro ordenamiento sí contempla los

(49) Cabe precisar que, ni el interés ni la legitimación se "invocan": se juzgan existentes o no existentes en base a la lo que se pretende, al contra quien se pretende y el por qué se pretende, esto es, en base a un juicio hipotético basado solo en las peticiones y alegaciones del demandante. Igual juicio debe hacerse si quien demanda es el Ministerio Público o un "procurador oficioso" (artículo 81 CPC), porque el primero bien podría no estar legitimado para pretender lo que pretende y el segundo es una suerte de "representante sin poder" (pero que actúa abiertamente por otro), por lo que el juicio sobre la legitimación e interés debe ser en relación a ese "otro" (la verdadera parte). De allí que cuando la segunda parte del primer párrafo del artículo IV del T.P. CPC señala que ni el Ministerio Público ni el procurador oficioso deben "invocar" ni interés ni "legitimidad" se comete un grave error.

(50) El artículo 427 CPC establece que el juez "declara improcedente la demanda cuando...", dejando sentado que es un deber y no una simple facultad.

(51) Naturalmente, a estar a la communis opinio, en el sentido de que el (llamado) "auto admisorio" de la demanda, no impide después apreciar de oficio la existencia de (Ilamémoslos así) "defectos procesales", ya sea en el auto de "saneamiento" del artículo 465 CPC o, conforme al último párrafo del artículo $121 \mathrm{CPC}$, en la sentencia (cualquier sentencia: la de primera instancia, la de segunda instancia y, cómo no, en la de casación), la apreciación de la falta de interés puede producirse, sin preclusiones, en cualquier estado y grado del proceso. En el sentido de que la falta de interés solo podría apreciarse hasta la sentencia de primera instancia, véase Avendaño Valdez (2010, p. 67); por su lado, Martel Chang (2019, p. 259) sostiene que "en la sentencia ya no cabe evaluar si el demandante tiene o no interés".

(52) “A la mano", porque, la mayoría de ellos, se pueden encontrar on line: desde aquella (que sería la más "confiable", pues le corresponde al principal autor del CPC) de Juan Monroy Gálvez (1994b, p. 124) que concibe al "interés para obrar" como la "necesidad de acudir al órgano jurisdiccional como único medio capaz de procesar y posteriormente declarar una decisión respecto del conflicto" (que es el concepto que, sin duda, "inspiró" a los anónimos autores del Decreto Legislativo 1070 a los efectos de modificar el artículo 6 de la Ley № 26872, Ley de Conciliación, en el sentido de que: "Si la parte demandante, en forma previa a interponer su demanda judicial, no solicita ni concurre a la Audiencia respectiva ante un Centro de Conciliación extrajudicial [...], el Juez competente al momento de calificar la demanda, la declarará improcedente por causa de manifiesta falta de interés para obrar"), pasando por aquella, apenas esbozada, de Ramirez Jimenez (2016, p. 57) para quien el "interés para obrar hace referencia al hecho de que el conflicto tenga relevancia jurídica y que sea presentado al ante el juez para recibir protección jurisdiccional”; hasta el texto de Juan Luis Avendaño Valdez (2010, p. 64-65) quien parece adherir al doble "concepto" funcional de interesse ad agire de Francesco P. Luiso, cual "selector para impedir el desarrollo de una actividad (de sustanciación, instrucción y decisión) relativa al fondo, cuando el pronunciamiento de fondo no es útil (interés al resultado), o bien cuando los efectos de la medida jurisdiccional pueden ser auto-producidos por el interesado [interés al medio]" (cito directamente de Luiso 2014, p. 96). Cabe advertir (a los lectores de los textos "a la mano") que Luiso es italiano (por lo que su "interés para obrar" es el del artículo $100 \mathrm{CPC}$ italiano, no muy distinto de nuestro artículo VI) y que reconduce funcionalmente el "instituto" del interesse ad agire a la (siempre peligrosa) "economía procesal" y en lo que él llama "carencia de interés en el medio" existe el eco de la "necesidad de tutela jurídica" (Rechtsschutzbedürfnis) de la doctrina alemana [en particular en su versión más perversa, es decir la de Adolf Schönke (1948, p. 132-152), para quien "[la] necesidad de tutela jurídica requiere un interés procesal, es decir un interés a la actuación del derecho y al mantenimiento de la paz mediante la invocación de los órganos de tutela jurídica", faltando necesidad de tutela jurídica "cuando alguien puede procurarse el resultado, a la que tiende, por vía extraprocesal" o cuando "está abierta otra vía especial de tutela jurídica o, en todo caso, una vía más simple, a través de la cual pueda obtenerse una decisión con la misma eficacia que por el otro camino" (Schönke, 1948, p. 141-142)]; mientras que lo que Luiso llama "carencia de interés en el resultado", es la tesis de Bruno Sassani (a quien se debe las dos maneras de entender el "interés-utilidad": utilidad en el medio/utilidad en el resultado) para quien el juicio sobre el interés "configura una prognosis de utilidad concreta del efecto jurídico pedido y, por tanto, una prognosis de práctica utilización del reconocimiento judicial del derecho hecho valer, de existir" (1989, p. 3 de la voz). La tesis de Sassani, que descarta que el interés pueda ser entendido como "utilidad/ medio", a mi modesto entender, constituye un feliz "retorno a lo antiguo" (esto es a la concepción del interés "a la francesa" del siglo $\mathrm{XIX)}$ con un lenguaje mucho más técnico.

(53) Así Nelson Ramirez Jimenez (2016, p. 58-59), expresando la communis opinio, señala que "un conflicto entre vecinos derivado de supuestos actos de 'brujería' cometido por uno de ellos no confiere derecho a un proceso judicial. Tampoco lo tienen las pretensiones que ya han merecido atención de la justicia y ya han sido resueltas en un determinado sentido, o que aún no tienen posibilidad de ser planteados como conflictos actuales porque falta el vencimiento de un plazo o no se ha configurado una condición estipulada por las partes. No hay se tiene [sic] interés actual cuando debe agotarse una vía administrativa previa que está en plano tránsito. Tampoco habrá interés para actuar ante la jurisdicción ordinaria si las partes han acordado discutir sus problemas ante un tribunal arbitral, o el derecho reclamado ha caducado manifiestamente". 
criterios para establecer si quien demanda cuenta con ese interés que le abre no solo la puerta del proceso sino la de la decisión de fondo: están, por las razones reiteradamente dichas, en nuestro artículo VI, el que justamente ofrece al buen intérprete los parámetros para juzgar si quien demanda "cuenta" o no con ese interés.

De hecho, si el intérprete lograra liberarse de todas las superestructuras conceptuales que montó la doctrina procesal alemana sobre el "concepto" de Rechtsschutzbedürfnis (necesidad de tutela jurídica) y, sobre sus huellas, la italiana del interesse ad agire, y se dedicara sin prejuicio a observar nuestro artículo VI debidamente concordado con el inciso 2 del artículo 427 CPC, advertiría que esta última disposición terminó (del todo inconscientemente) por completarlo: aquél que demanda sin tener un "legítimo interés económico o moral”, se enfrentará a una declaración de "improcedencia”(54), esto es, no podrá obtener una decisión de fondo.

\section{Los "parámetros" del artículo VI: el "legítimo interés económico o moral"}

Ahora bien, si el interés al que alude el artículo VI consiste en aquella utilidad que podría producirle al demandante la estimación de su demanda -una utilidad, hay que remarcarlo, a "medirse" en vía simplemente hipotética, esto es en base al solo tenor de la demanda-al establecer que la tal interés pueda ser no solo económico (o si se prefiere, material o patrimonial) sino también moral (o si se prefiere, inmaterial, existencial o, simplemente, no patrimonial) permite cubrir todo el espectro de ventajas sustanciales que potencialmente podrían producirse en la esfera del demandante con la intervención de los órganos jurisdiccionales ${ }^{(55)}$.

Es decir, no solo un "interés" estrictamente económico (como, por poner unos ejemplos obvios, el de aquél que afirmándose propietario actúa en reivindicación para retomar la posesión de un bien que afirma ilegítimamente poseído por el demandado; el del afirmado vendedor que actúa en resolución para obtener una decisión que reintegre el bien vendido a su esfera patrimonial y, eventualmente, para quedar liberado de su obligación de entregar el bien al demandado; el del afirmado acreedor en obtener la declaración de nulidad de un acto de disposición, que dice simulado, celebrado por quien dice que es su deudor, para lograr que ese bien retorne al ámbito de la responsabilidad patrimonial de su afirmado deudor, etc.), sino también moral, en donde no es tan obvio concebir el interés en términos de "utilidad" (como el del afirmado autor de una obra para que se declare su autoría, aunque sus derechos patrimoniales hayan sido cedidos a otro; el de aquél que lamenta haber sido indebidamente descalificado en un concurso para un puesto, aunque ya no tenga posibilidad de ganarlo, para que se declare que sí tenía los méritos profesionales para acceder a él; el de aquel que se lamenta de la usurpación del nombre de su padre fallecido, para lograr el cese del uso que desprestigia, o aprovecha indebidamente, la reputación del nombre familiar, etc.).

Pero, este interés (esta utilidad, esta ventaja sustancial) que se propone el demandante obtener, dice el artículo VI, debe ser "legítimo". Respecto a cómo deba entenderse la legitimidad del interés, entre nosotros, se ha dicho de todo (y, a la vez, nada) ${ }^{(56)}$. Ciertamente el epíteto

(54) La palabra "improcedencia" es equivalente, a todos los efectos, a la irrecevabilité francesa. Hay que tener presente que en la terminología que nos ha impuesto el CPC, la inadmisibilidad está referida a defectos procesales susceptibles de subsanación, mientras que la improcedencia a defectos insubsanables. Hay igualmente que precisar que en algunas partes del CPC se usa la palabra "rechazo" (a comenzar por el último párrafo del artículo $426 \mathrm{CPC}$ ), término del todo equivalente al de improcedencia (cfr. el segundo párrafo del artículo 121 CPC y el artículo 636 CPC en que se usa la palabra "rechazo" de la demanda).

(55) La terminología del artículo $\mathrm{VI}$, sin duda, resiente del desgaste del tiempo en que fue formulada. Si pensamos que ella expresa ideas del S. XIX, en donde los derechos inherentes a la persona humana estaban todos en construcción, el que el texto diga que un interés "moral" (por contraposición al económico) pueda "autorizar una acción", es algo que en lugar de criticar, deberíamos elogiar pues la expresión "interés moral", sin duda ambigua, tiene toda la potencialidad que tienen las "cláusulas generales" de expandir el área (y formas) de lo tutelable jurisdiccionalmente.

(56) Monroy Gálvez (1994a, p. 46), tras decir que el concepto de interés del artículo VI "no es procesal" (como, en efecto, no es, pues lo procesal es la consecuencia de no tenerlo), señala que la legitimidad del interés puede ser entendida de dos maneras: como legal ("que tenga apoyo o sustento en el ordenamiento jurídico") o legitimado ("que tenga fundabilidad, es decir, amparo o razón en el mismo sistema"); de entenderse lo "legítimo" como "legal, sería una "afirmación ( $¿$ ?) absolutamente tautológica" pues en un proceso solo se puede discutir "un conflicto de intereses con relevancia jurídica"; de entenderse lo legítimo como "tener la razón", "sería "una afirmación equivocada", pues si así fuera nadie podría demandar [me pregunto si esa misma disyuntiva la aplicaría el autor al "interés legítimo" -escrito por él en el texto del artículo 100 CPC- que tiene que "invocar" el tercero en su instancia de intervención]. Por su lado, Rubio Correa (2008, p. 119) señala que: "La expresión legítimo interés dentro del Código Civil, parece referirse a aquellos intereses exigibles a su arbitrio por el interesado. Se descartarían, por tanto, los intereses de carácter genérico $[\ldots]$ y los de naturaleza expectaticia". 
"legítimo" es siempre ambiguo, y lo es más cuando califica otra locución ambivalente cual es el "interés"(57).

Sin embargo, si nos atenemos a los significados que nos dan los Diccionarios, darle el apropiado al "legítimo" del artículo VI, no debería ser tan complejo. Es así que si para nuestro DRAE el adjetivo "legítimo" puede significar tanto como "conforme a las leyes" o, simplemente, "lícito" (que, a su vez, concibe como "justo, permitido, según justicia y razón") y la locución "interés legítimo" como el "interés de una persona reconocido y protegido por el derecho", el "legítimo" del artículo VI no puede sino significar "conforme a Derecho", pero no (o no solamente) el Derecho como conjunto de normas positivizadas, sino como conjunto de principios y valores que integran nuestro ordenamiento jurídico ${ }^{(58)}$.

En suma, el "legítimo interés" del artículo VI está a indicarnos que el que demanda no puede pretender "cualquier" ventaja, cualquier utilidad, económica o moral, sino una que sea compatible con nuestro sistema jurídico. Dicho en términos procesales: una demanda será improcedente cuando la utilidad que pretende obtener el demandante es "ilegítima", esto es, "manifiestamente" contraria al ordenamiento jurídico( ${ }^{(59)}$.

\section{El limitado alcance práctico del artículo VI}

Si esto es así, si en buena cuenta lo que el CPC llama (impropiamente) "interés para obrar" debe enjuiciarse en base a los parámetros que nos establece nuestro artículo $\mathrm{VI}$, la pregunta que surge espontánea es: ¿qué tanta probabilidad habría que se termine declarando improcedente una demanda por carencia de interés? Pues muy poca. Y es muy poca porque, por lo general, lo que se pretende se presenta, prima facie, como legítimamente útil al demandante. Es por ello que la gran mayoría de la doctrina italiana y alemana - sea cual fuere el "concepto" que se maneje de interesse ad agire o de Rechtsschutzbedürfnis- considera que, en sustancia, solo tiene relevancia en los procesos cuyo objeto es obtener una sentencia meramente declarativa, más no así cuando se pretende una sentencia de condena o

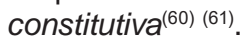

(57) Y es considerado "ambiguo" también en aquellos ordenamientos que han así calificado al interés como presupuesto o condición de admisibilidad de la demanda (rectius, para obtener una decisión de fondo). Tal es el caso de los franceses -que expresamente, en el artículo 31 de su CPC exigen que el interés sea légitime- y de los belgas -que, pese a que el artículo 17 de su Code judiciaire ("L'action ne peut être admise si le demandeur n'a pas qualité et intérêt pour la former" [La acción no puede ser admitida si el demandante no tiene calidad e interés para formularla]), la jurisprudencia, la más de las veces equivocadamente, lo exige. Sobre este último ordenamiento, véase el punzante trabajo de Rafaël Jafferali (2012, p. 253-265), con interesantes referencias jurisprudenciales y doctrinarias no solo belgas sino también francesas.

(58) Señala Labbée (1995, p. 42-43) que el interés legítimo del artículo 31 del CPC francés no debe de ser confundido con el derecho subjetivo (el interés expresamente protegido por la ley), sino que debe entenderse en sentido lato, como equivalente a "serio", esto es, que lo que pretende el demandante no revele que esté movido solo por un espíritu de chicana, sin ninguna posibilidad de obtener alguna ventaja.

(59) Nada muy distinto, por cierto, de aquello que establece el inc. 5 del artículo 427 CPC que hace improcedentes las demandas cuyo "petitorio [sea] jurídica [...] imposible". La "posibilidad jurídica" de lo pedido, corresponde a la "voluntad de la ley" cual primera condición de la acción en la construcción chiovendiana. Fue llamada así por Liebman, también, como "condición de la acción" (1962, p. 46: "posibilidad jurídica, que es la admisibilidad en abstracto de la medida pedida") y luego abandonada a partir de la tercera edición de su Manuale (el que fue traducido por Sentís Melendo (véase Liebman, 1980)] para entrar a subsumirla, justamente, como parte del interesse ad agire.

(60) Como ya lo sostenía Chiovenda, sobre las huellas de la propia doctrina alemana de su época (véase nota 29). Una versión estándar de la concepción actual de la "necesidad de tutela jurídica" (Rechtsschutzbedürfnis) en Alemania, en razón de los tipos de demanda se puede encontrar en Leible (1998, p. 175, en general; p. 169, respecto a la demanda de condena; p. 170-171 respecto a demanda meramente declarativa) y p. 174, respecto a la demanda constitutiva).

(61) No me ocupo en el texto del "interés para accionar" en el área de la tutela ejecutiva y de la cautelar no porque sea irrelevante, sino porque el discurso sería muy extenso. Sin embargo, no puedo dejar de decir que habría una carencia de interés in executivis (en los términos del texto), por ejemplo, cuando el ejecutante (en una ejecución dineraria) pretendiera "satisfacer" su crédito con cargo a un bien del ejecutado totalmente "afectado" (hipotecado, embargado) en su valor de cambio a favor de otros créditos o con un bien cuyo valor de cambio sirviera simplemente para cubrir los gastos de la ejecución. En ambos casos, de llevarse adelante la ejecución, el ejecutante no obtendría ninguna real y concreta "utilidad" (seguiría siendo tan acreedor como antes). Por lo que atañe al interés en obtener una tutela cautelar, buena parte de la doctrina italiana (a comenzar por Attardi, 1962, p. 841 y sucesivas) considera que él se identifica con el periculum in mora. Ciertamente, si no es concebible que venga otorgada tutela cautelar si es que no hay algún peligro (de infructuosidad o de mera tardanza, por usar la clásica dicotomía calamandreiana) que neutralizar (en neutralizar el periculum estaría la "utilidad" del solicitante), considerar la presencia del periculum en términos de "interés para accionar" o, en cambio, en términos de (lo que podemos llamar) el "mérito cautelar", por el tipo de juzgamiento que se realiza en el ámbito cautelar, se resuelve en un simple problema terminológico. 
Y este limitado alcance tiene sentido por cuanto, normalmente ${ }^{(62)}$, cuando se demanda que se condene al demandado a un determinado comportamiento (pago de una suma de dinero, entrega de un bien, un hacer o un no hacer), la utilidad sustancial del demandante está, por lo general, descontada(63); lo propio ocurre cuando estemos ante una petición de tutela constitutiva , en donde, como se suele decir, el interés está in re ipsa, en cuanto basta que se aleguen los hechos que, en concreto, se subsumen en el supuesto de hecho (la fattispecie) sustancial (así: el incumplimiento para obtener la declaración de resolución de un contrato con prestaciones recíprocas; el dolo para obtener la anulación de un acto; etc.), para que el tema de la carencia de interés esté fuera de juego ${ }^{(64)}$.
En cambio, tratándose de pedidos de tutela de mera declaración, la situación cambia, en particular, cuando estemos ante pedidos declarativos atípicos (para los típicos, como el de nulidad negocial, el interés está dado por la propia subsunción de los hechos en alguna de sus causales). No por nada, ya en el siglo XIX, los alemanes al darse su ordenamiento procesal civil unitario de 1877 (la ZPO), solo exigieron la existencia de interés jurídico [rechtliches Interesse] en el primer párrafo de su § 256 tratándose de demandas meramente declarativas ${ }^{(65)}$.

(62) Digo "normalmente", porque, a priori, no se puede excluir que en algún caso pueda presentarse una carencia de interés en el ámbito de la tutela de condena. Particular es el caso en el que se pretenda una condena "a futuro" (esto es, que se demande la condena del deudor antes del vencimiento del plazo). En nuestro sistema la única hipótesis típica prevista por la ley está contenida en el artículo 594 CPC, en relación al proceso de desalojo que a la letra dispone: "El desalojo puede demandarse antes del vencimiento del plazo para restituir el bien. Sin embargo, de ampararse la demanda, el lanzamiento sólo puede ejecutarse luego de seis días de vencido el plazo". Fuera de este caso, considero que pueda demandarse la emisión de una sentencia de condena "a futuro", cuando exista una (alegada) amenaza de incumplimiento a los efectos de obtener un título ejecutivo (la sentencia) que le permita, luego, de verificarse el incumplimiento, ingresar a la ejecución judicial. En la obtención del título ejecutivo está la "utilidad".

(63) Suele decirse que, si quien demanda la condena al cumplimiento de una obligación sujeta a condición no verificada, a un plazo no vencido o, en un contrato con prestaciones recíprocas, habiendo incumplido su propia prestación, carecería de "interés para obrar". Al margen de que nadie en su sensato juicio demanda el cumplimiento diciendo que la prestación no es aún exigible, la no verificación de la condición, el vencimiento del plazo (salvo, que abiertamente se pida una condena "a futuro", véase nota anterior) o el cumplimiento de la prestación a cargo del demandante, son cuestiones de fondo (que por lo general son levantadas por el demandado), esto es, relativas a la existencia del derecho alegado y no condiciones para decidir el fondo. Aquella fue la posición de Chiovenda ( $\mathrm{y}$, sobre sus huellas, Calamandrei), pero recuérdese que para Chiovenda (y para Calamandrei), el interesse ad agire era una condición para obtener una sentencia favorable y el interesse ad agire en condena estaba dado por una situación contraria a derecho, esto es, por el incumplimiento (véase Chiovenda, 1954, p. 217; Calamandrei, 1962, p. 270). En Italia, abandonada la concepción de la acción como derecho a la sentencia favorable, prácticamente ya nadie sostiene que la no verificación de la condición o el vencimiento del plazo configure una carencia de interesse ad agire: sobre el punto, véase Proto Pisani (1973, p. 1073-1074), para quien la solución es de derecho sustancial, esto es, de cómo se entienda la situación del derecho sometido a condición o a plazo; en similar sentido, Consolo (2015, p. 579).

(64) Incluso frente a lo que suele llamarse tutelas constitutivas "no necesarias", esto es, cuando el efecto modificativo pretendido se podría lograr extrajudicialmente (caso típico, la resolución por incumplimiento conforme al artículo 1429 CC) o por un procedimiento extrajudicial (como el divorcio notarial o administrativo municipal de la Ley № 29277). No me consta que algún juez de la República haya declarado improcedente una demanda de declaración de resolución por incumplimiento o una demanda de separación convencional, por no haberse "optado" por una intimación para cumplir ex artículo 1429 CC o por poder obtener la declaración de separación en la vía extrajurisdiccional.

(65) Transcribo el texto del § 256 ZPO: "Feststellungsklage: Auf Feststellung des Bestehens oder Nichtbestehens eines Rechtsverhältnisses, auf Anerkennung einer Urkunde oder auf Feststellung ihrer Unechtheit kann Klage erhoben werden, wenn der Kläger ein rechtliches Interesse daran hat, dass das Rechtsverhältnis oder die Echtheit oder Unechtheit der Urkunde durch richterliche Entscheidung alsbald festgestellt werde" [Se puede promover una acción para la declaración de la existencia de una relación jurídica, para el reconocimiento de una escritura o para la declaración de la falsedad de la misma, cuando el actor tiene un interés jurídico en que la relación jurídica sea declarada de inmediato por declaración judicial]. La disposición alemana ha sido tomada por muchos códigos latinoamericanos. Así, el artículo 11.3 del Código General del Proceso uruguayo de 1988: "El interés del demandante puede consistir en la simple declaración de la existencia o inexistencia de un derecho, aun cuando éste no haya sido violado o desconocido, o de una relación jurídica, o de la autenticidad o falsedad de un documento". Por el artículo 16 del Código de Procedimiento Civil venezolano de 1990: "Para proponer la demanda el actor debe tener interés jurídico actual. Además de los casos previstos en la Ley, el interés puede estar limitado a la mera declaración de la existencia o inexistencia de un derecho o de una relación jurídica. No es admisible la demanda de mera declaración cuando el demandante puede obtener la satisfacción completa de su interés mediante una acción diferente". Por el artículo 19 Código del Proceso Civil brasileño de 2015 (repitiendo el artículo 4 del Código de 1973) que establece: "El interés del actor puede limitarse a la mera declaración de certeza: I.- de la existencia, de la inexistencia del modo de ser de una relación jurídica; II. De la autenticidad o falsedad de un documento", agregando, en su artículo 20 que: "Es admisible la acción de mera declaración de certeza, aunque haya habido violación del derecho". Nosotros, en cambio, nos limitamos a decir, en el artículo III del TP CPC, que el proceso tiene por finalidad, junto con la de resolver un conflicto de intereses, la de "eliminar una incertidumbre jurídica", por lo que no tenemos ningún límite preciso sobre el alcance de la tutela meramente declarativa. 
Es pues en el área de la tutela meramente declarativa en donde encontrará particular relevancia la indagación del interés en los términos del artículo $\mathrm{VI}$, en el sentido de que presentada una demanda en la que se pretende solo la declaración de existencia o inexistencia de un derecho (o de lo que fuere) ${ }^{(66)}$ se tendrá que evaluar la utilidad (económica o moral) que tal declaración puede producir en la esfera jurídica del demandante, pues si la declaración de nada le sirve, el juez estará exonerado de emitir una decisión de fondo y, del todo legítimamente, podrá declarar improcedente la demanda ex inciso 2 del artículo 427 CPC.

De hecho, es en esta área en que valen las prevenciones en el sentido de que la tutela pedida debe repercutir de manera efectiva y no hipotética en la esfera jurídica del demandante, en cuanto los órganos jurisdiccionales no pueden "limitarse a emitir dictámenes o a hacer declaraciones genéricas acerca de hipotéticas situaciones a los simples efectos de ilustrar a las partes sobre el comportamiento más adecuado" (Montero Aroca, 2007, p. 169)(67).

\section{El interés del artículo VI cual situación "legitimante"}

Si el tema del interés en accionar, por lo general, adquiere relevancia en el área de la tutela meramente declarativa, también lo tiene en aquellos supuestos en los que el legislador mismo ha dejado abierta la legitimación para pretender "algo" siempre que se tenga "interés".

Así, sin pretensión de exhaustividad, se deja abierta la legitimación en los siguientes supuestos: (i) en el CC, art. 49 (en la declaración de ausencia), art. 129 (en la afectación de los bienes de una fundación que no ha logrado inscribirse a otras fundaciones), art. 220 (en la declaración de nulidad de un acto), art. 275 (en la declaración de nulidad de matrimonio, en el que al "legítimo interés" se agrega que deba de ser "actual"), art. 399 (en la impugnación de reconocimiento de maternidad o paternidad), art. 599 (en la designación de curador especial de bienes), art. 956 (en la reparación, demolición u otra medida preventiva respecto de una obra ruinosa); y (ii) en la Ley General de Sociedades (LGS): art. 15 (en el otorgamiento de escritura de acuerdos sociales), art. 35 (en la nulidad del pacto social), art. 36 (en que se ordene judicialmente la inscripción de la sentencia de nulidad de un acuerdo social), art. 150 (en la declaración de nulidad de un acuerdo social contrario a normas imperativas, que incurran en causales establecidas en la propia LGS o en el CC).

Entendido el interés del artículo VI como aquella utilidad (económica o moral) que la tutela pedida puede producir en la esfera jurídica del demandante, en estos casos la determinación de la legitimación -siempre en vía hipotética, esto es, solo conforme al tenor de la demanda-en pedir lo demandado, pasa por una previa evaluación del "interés". Es decir, la existencia del concreto interés del demandante, evaluada conforme a los parámetros del artículo VI, funge como situación legitimante ${ }^{(68)}$.

\section{Interés para "contestar la acción"}

La relectura del artículo $\mathrm{VI}$ que este trabajo se ha propuesto, no estaría completa si no se abordara también el "interés" visto desde la óptica del otro personaje del proceso: el demandado. In primis, parecería que el artículo VI al exigir la presencia del "interés" también para "contestar" una "acción"

(66) En el sentido de que el artículo 100 CPC italiano (idéntico al artículo 36 del CPC de 1865, que, como se ha visto en el texto, constituye el más remoto antecedente textual de nuestro artículo $\mathrm{VI}$ ), más que restringir el área de tutela meramente declarativa la expande también hacia la mera declaración de "temas de decisión" (Vorfragen) o partes de una situación sustancial (por ejemplo, que no ha habido incumplimiento contractual) distintas de la usual mera declaración de la existencia o inexistencia de un derecho subjetivo o de una relación jurídica, véase Marinelli (2005, p. 141 y ss).

(67) Sin embargo, Montero Aroca no deja de decir que "ante la pretensión formulada por un particular, que decide gastar su dinero y emplear su tiempo acudiendo a los tribunales, será difícil en el caso concreto negar la existencia de todo interés, por lo menos en las situaciones que podemos considerar comunes y dejando a un lado las patológicas". En similar sentido, Leible (1998, p. 176), quien advierte la peligrosidad de tratar de ubicar "la necesidad general de tutela jurídica" y aconseja "la prudente y reservada utilización de tal exigencia", por lo que, "si no hay circunstancias muy especiales, siempre se debe reconocer una necesidad de protección jurídica".

(68) La expresión "situación legitimante" es de Bruno Sassani (1989, p. 12), quien, pese a la contraria opinión de casi toda la doctrina procesal italiana (que reconduce el fenómeno exclusivamente al área de la legitimación), señala que "si es verdad que los conceptos de interés y de legitimación -en sí tomados- deben ser mantenidos distintos, también lo es que nada impide que, en hipótesis taxativas de ley, el interés en accionar (el interés en accionar en sentido propio invocado por el artículo 100) pueda presentarse como elemento de integración del supuesto de hecho de la legitimación del actor". 
Hacia una reinterpretación del artículo VI del Título Preliminar del Código Civil: en la búsqueda de los parámetros del "interés para obrar"

Towards a reinterpretation of article VI of the Preliminary Title of the Civil Code: in search of the parameters of the "standing to sue"

estaría estableciendo una inútil obviedad, porque desde el momento que es el demandante quien coloca a un sujeto como demandado, su "interés" parecería estar descontado. Sin embargo, a priori, no hay que excluir toda relevancia práctica a esta parte del artículo VI, en particular si no se identifica el "contestar" con el acto previsto en el artículo 442 CPC, sino con el contenido concreto de los actos defensivos del demandado.

Sobre el particular hay que tener presente que cuando alguien viene demandado, el CPC le impone la carga(69) de tomar posición sobre la demanda dirigida en su contra. Y para liberarse de esta carga un demandado podría (en orden lógico y cronológico): (i) plantear, para liberarse solo del proceso, meras cuestiones de orden procesal (es decir, plantear lo que el artículo 446 CPC Ilama "excepciones"); y/o, (ii) en el acto de contestación de la demanda, a) asumir una posición de mera defensa (inciso 2 del artículo 442 CPC), esto es, negar los hechos constitutivos del derecho alegados por el demandante o admitir (todos o algunos) de esos hechos, más no sus consecuencias jurídicas (inciso 2 del artículo 442 CPC), o b) excepcionar, esto es, alegar otros hechos (inciso 4 del artículo 442 CPC), hechos estos que pueden ser impeditivos, modificativos o extintivos del derecho afirmado por el demandante.

Y es justamente sobre estas últimas alegaciones que sí podría realizarse un "juicio" de utilidad bajo los parámetros del artículo VI, pues como decían los antiguos reus in excipiendo fit actor ${ }^{(70)}$. Naturalmente, si el artículo VI exige la presencia del interés (legítimo, económico o moral) para hacer procedente una demanda (esto es, por si no está aún claro, para que se pueda obtener una decisión de fondo), es evidente que ese enfoque de utilidad aplicado a las alegaciones del demandado, no puede conducir a la improcedencia de su "contestación" (es decir, del acto del artículo 442 CPC), sino solo a un juicio (siempre hipotético y, en este caso, en armonía con el derecho de defensa) sobre la utilidad que esas concretas alegaciones podrían producir en la esfera del demandado, a los efectos de admitirlas entre aquellas que deben ser analizadas al pronunciarse sobre el fondo o, por el contrario, a excluirlas ${ }^{(71)}$.

\section{Reflexiones conclusivas}

El presente trabajo se había propuesto verificar si realmente el artículo VI es un dispositivo superfluo o más bien conserva alguna utilidad en nuestro ordenamiento jurídico. En concepto de quien escribe, su contenido no solo tiene "alguna" utilidad, sino una "gran" utilidad.

De hecho, en tiempos en que tanto se habla (y poco se hace...) sobre la efectividad de la tutela jurisdiccional y sobre la reconciliación de las quebradas - por tantas vanas teorías procesalistas- relaciones entre el derecho sustancial y el proceso, no parece acertado considerar la presencia del artículo VI como "una excentricidad, a la fecha absolutamente inútil" (Monroy Gálvez, 1994a, p. 42).

En efecto, como se ha tratado (y, se espera, logrado) demostrar en el presente trabajo, el artículo VI es el fiel relejo de la máxima (de pura racionalidad) francesa "el interés es la medida de las acciones”, tal como venía interpretada por la doctrina y jurisprudencia europea de derivación francesa en el siglo XIX. De allí que se diga que no cualquier "interés" autoriza la "acción", sino que, in primis, debe tratarse de un interés legítimo (entendido como no contrario al conjunto de valores y principios del ordenamiento jurídico), pudiendo ser éste económico (que es lo usual) sino también meramente "moral".

Igualmente, se ha tratado (y se espera logrado) demostrar que el ese interés legítimo evocado por el artículo VI, no es más que la concreta "utilidad" (la ventaja, el provecho) económica o moral que un pronunciamiento como el pedido le daría al demandante de ser estimada su demanda. En tal línea, si lo pedido, de ser estimado, no le provocara ninguna ventaja al demandante (lo dejaría en la misma situación sustancial), nos encontraríamos ante una carencia de "interés en accionar".

Por último, se ha tratado ( $y$, se espera, logrado) demostrar, que el artículo VI es una norma incompleta, por cuanto, a diferencia de

(69) Dice, en efecto, el artículo 442 CPC que en (el acto) de contestación de la demanda "el demandado debe...". Es obvio, que no estamos ante un "deber", sino ante una "carga", pues el demandado es "libre" de hacerlo o no, y si no lo hace pierde la ocasión para adquirir las ventajas que su comportamiento positivo le habrían podido producir (aunque con las consecuencias tan severas que establece el CPC, esa carga se acerca mucho a un auténtico deber).

(70) "Se puede hablar de interés en contradecir, en el sentido del artículo en examen [artículo $100 \mathrm{CPC}$ italiano], solamente cuando el demandado in excipiendo fit actor, es decir en referencia a las concretas posiciones sustanciales que él asume como su defensa, es decir, en definitiva, a los intereses que él hace valer" (Satta, 1954, p. 169).

(71) En la dinámica del CPC, ello debería ocurrir al momento de "fijación de puntos controvertidos" (artículo 468 CPC). 
sus auténticas fuentes, no establece la consecuencia de la falta de interés en el demandante. Sin embargo, la consecuencia (procesal) de la carencia de interés (entendido como concreta utilidad económica o moral) está establecida en el inc. 2 del artículo 427 del Código Procesal Civil de 1993 que sanciona con la improcedencia a aquellas demandas planteadas por un sujeto que carece "manifiestamente" (es decir, en base a las meras alegaciones contenidas en la demanda) de "interés para obrar". En tal línea, el Código Procesal Civil de 1993, completó el "supuesto de hecho" (la fattispecie) del artículo VI, estableciendo ya expresamente la consecuencia de la carencia ese interés exigido por el artículo VI.

Por tanto, el "interés en accionar" del artículo VI es el mismo "interés para obrar" del Código Procesal Civil. De allí que el artículo VI sea preceptivo para el juez a fin de establecer si un sujeto que demanda cuenta con ese "interés" que le permita obtener una decisión de fondo sobre su pretensión de tutela. En tal línea, el artículo VI contiene los "parámetros" para "medir" ese interés.

En consecuencia, el artículo VI no solo tiene "alguna" utilidad, sino una "gran utilidad", por cuanto:

a) es útil porque permite develar lo que se esconde tras el (mal llamado) "interés para obrar" concebido por el Código Procesal Civil como una "condición de la acción" (rectius, como un presupuesto para la emisión de una decisión de fondo) cuya ausencia "manifiesta" hace improcedente ex inciso 2 del artículo 427 CPC una demanda;

b) es útil porque establece los parámetros para "medir" objetivamente el "interés" cual legítima utilidad económica o moral que podría obtener el demandante de la estimación de su demanda;

c) es útil porque permite ubicar los escasos supuestos en los que puede realmente faltar ese interés concebido como legítima utilidad económica o moral (fundamentalmente en el área de la tutela meramente declarativa, pues en las áreas de la tutela de condena y constitutiva está, en la generalidad de los casos, in re ipsa);

d) es útil, porque permite, además, "medir" en concreto quién se encuentra legitimado para plantear una pretensión cuando el legislador se la concede al que tenga "legítimo interés";

e) es útil, finalmente, porque ese "interés moral" que aparece en su texto tiene toda esa potencialidad inherente a su ambigüedad para abrir las puertas de la tutela jurisdiccional a pretensiones basadas en situaciones jurídicas sustanciales no patrimoniales en búsqueda de reconocimiento judicial.

Hace muchos años, Enrico Allorio, frente a la concepción (como mínimo autoritaria) de Adolf Schönke sobre la "necesidad de tutela jurídica" cual "concepto procesal fundamental", concluía su ensayo polémico señalando que la "doctrina de la necesidad-interés pretende introducir una especie de fiscalización causal sobre los actos procesales: a la norma procesal que reconoce ciertos efectos a ciertas iniciativas de parte en ciertas situaciones, sobrepone una especie de revisión paternal no de la legalidad del acto, sino de su conveniencia según una medida de juicio, que en su aplicación no puede por menos de resultar arbitraria" [cursivas agregadas] (Allorio, 1954, p. 114). Yo creo que nuestro artículo VI, repito, bien interpretado, sirve de efectivo antídoto a los desvaríos arbitrarios que el concepto de "interés para obrar" (dejado en blanco por el Código Procesal Civil) puede provocar sobre la efectividad de la tutela jurisdiccional.

\section{Referencias bibliográficas}

Allorio, Enrico (1954). Necesidad de tutela jurídica. Traducido por Niceto Alcalá Zamora y Castillo. Revista de la Facultad de Derecho de México 14(4), p. 89-114

Attardi, Aldo (1962). Interesse ad agire [voz]. (Vol. VII), de Novissimo Digesto italiano, (p. 840-844). Turín: UTET.

Avendaño Valdez, Juan Luis (2010). Interés para obrar. Thēmis. Revista de Derecho, (58) p. 63-69.

Betti, Emilio (1932). Ragione e azione. Rivista di diritto processuale civile. Parte I, p. 205-237.

Borsari, Luigi (1878). I/ Codice italiano di procedura civile. Cuarta edición. Turín: Unione TipograficaEditrice Torinese.

Calamandrei, Piero (1962). Instituciones de derecho procesal civil según el nuevo Código [1943]. Traducido por Santiago Sentís Melendo. Vol. I. Buenos Aires: Ejea.

Calle, Juan José (1912). Código de Procedimientos Civiles. Lima: Sanmartí.

Carré, G. L. J. (1841). Le leggi della procedura civile. Prima versione italiana. Traducido por Francesco De Filippo y Gennaro De Filippo. Vol. I. Nápoles: Tipografia Reale.

(1846) Lois de procédure civile. Tercera edición. Vol. I. Bruselas: Meline, Cans et Compagnie.

Chiovenda, Giuseppe (1993). Azione di mero accertamento [1937]. En A. Proto Pisani (edit), Saggi di diritto processuale civile (1894-1937) (Vol. III, p. 51-73). Milán: Giuffrè. 
Hacia una reinterpretación del artículo VI del Título Preliminar del Código Civil: en la búsqueda de los parámetros del "interés para obrar"

Towards a reinterpretation of article VI of the Preliminary Title of the Civil Code: in search of the parameters of the "standing to sue"

(1954). Instituciones de derecho procesal civil. Traducido por Emilio Gómez Orbaneja. (Vol. I). Madrid: Revista de Derecho Privado.

Chiovenda, José (1924). Principios de derecho procesal civil. Traducido por José Casais y Santaló. (Vol. I). Madrid: Reus.

Cintra, Antonio Carlos De Araujo, Ada Pellegrini Grinnover, y Cándido Rangel Dinamarco (2003). Teoria geral do processo. (19va ed.). Sao Paulo: Malheriros.

Cipriani, Franco (1991). Storia di processualisti e di oligarchi. La procedura nel Regno d'Italia (1866-1936). Milán: Giuffrè.

Consolo, Claudio (2015). Spiegazioni di diritto processuale civile. (10ma ed., Vol. I). Turín: Giappichelli.

Espinoza Espinoza, Juan (2015). Introducción al derecho privado. Lima: Instituto Pacífico.

Gianturco, Emmanuele (1921). Istituzioni di diritto civile italiano. Edizione riveduta e coordinata al diritto vigente dal Prof. Carlo Lessona. Florencia: Barbèra.

Grossi, Paolo (2000). Scienza giuridica italiana. Un profilo storico 1860-1950. Milán: Giuffrè.

Jafferali, Rafaël (2012). "L'intérêt légitime à agir en réparation: Une exigence... illégitime?" Journal des Tribunaux, (6473), p. 253-265.

Labbée, Pascal (1995). Introduction au droit processuel. Lille: Presses Universitaires de Lille.

Leible, Stefan (1998). Proceso civil alemán. Segunda edición. Medellín: Diké-Konrad Adenauer Sfiftung.

Leon Barandiarán, José (1985). “Exposición de Motivos y Comentarios al Título Preliminar." En Exposición de Motivos y Comentarios, editado por Delia Revoredo de Debakey. Lima: Studium.

Liebman, Enrico Tullio (1962). L'azione nella teoria del processo civile [1950]. En Problemi del processo civile, (p. 18-53). Nápoles: Morano.

(1980). Manual de derecho procesal civil. Traducido por Santiago Sentís Melendo. Buenos Aires: Ejea.

. (2007). Manuale di diritto processuale civile. Principi. Sétima edición. Milán: Giuffrè.

Loreto, Luis (1970). Contribución al estudio de la excepción de inadmisibilidad por falta de calidad [1940]. En Ensayos jurídicos, (p. 15-76). Caracas: Favretón.

Luiso, Francesco P (2014). Istituzioni di diritto processuale civile.(4ta ed.). Turín : Giappichelli.

Mancini, P. S., G. Pisanelli, y A. Scialoja (1855). Commentario del Codice di Procedura Civile per gli Stati Sardi con la comparazione degli altri Codici Italiani, e delle principali Legislazioni straniere. (Vol. II). Turín: Unione Tipografico-Editrice Torinese.

Marinelli, Marino (2005). La clausola generale dell'art. 100 c.p.c. Origini, metamorfosi e nuovi ruoli. Trento: Università degli Studi di Trento.

Martel Chang, Rolando (2019). Interés para obrar. En Postulación del proceso, coordinado por Renzo Cavani, (p. 247-262). Lima: Ius et veritas.
Monroy Gálvez, Juan (1994a). El Artículo VI del Título Preliminar del Código Civil Peruano de 1984. Thēmis-Revista de Derecho, (30), p. 37-47.

(1994b). Las excepciones en el Código Procesal Civil peruano. Thēmis-Revista De Derecho, (27-28), p. 119-129.

Montero Aroca, Juan (2007). De la legitimación en el proceso civil. Barcelona: Bosch.

Motulsky, Henri (1973). Le droit subjectif et l'action en justice [1964]. En Écrits. Tome 1. Études et notes de procédure civile, (p. 85-100). París: Dalloz.

Nasi, Antonio (1972). Interesse ad agire [voz]. (Vol. XXII) En Enciclopedia del diritto, (p. 28-47). Milán: Giuffrè.

Orestano, Riccardo (1959). Azione in generale. a) Storia del problema. Vol. IV, de Enciclopedia del diritto, (p. 785-829). Milán: Giuffrè.

Perrot, Roger (1975). II nuovo e futuro Codice di procedura civile francese. Rivista di diritto processuale, p. 228-264.

París: Montchrestien.

(1995). Institutions judiciaires. (7ma ed.).

Picardi, Nicola, y Alessandro Giuliani (2004). Testi e documenti per la storia del proceso. XIII. Codice di procedura civile del Regno d'Italia, 1865. Milán: Giuffrè.

Poncet, M (1835). Traité des jugemens, précédé du Traité des actions. Bruselas: Librairie de Jurisprudence de $\mathrm{H}$. Tarlier.

Priori Posada, Giovanni (2003). Art. VI del Título Preliminar del Código Civil. Vol. I, de Código Civil comentado, (p. 64-70). Lima: Gaceta Jurídica.

Proto Pisani, Andrea (1973). Dell'esercizio dell'azione. Vol. I, de Commentario del Codice di procedura civile. Libro Primo, dirigido por Enrico Allorio, (p. 1046-1252). Turín: UTET.

Ramirez Jimenez, Nelson (2016). Art. IV. Principios de iniciativa de parte y conducta procesal. Vol. I, de Código Procesal Civil comentado, coordinado por Renzo Cavani, (p. 56-61). Lima: Gaceta Jurídica.

Rocco, Alfredo (1906). La sentenza civile. Turín: Fratelli Bocca.

Rocco, Ugo (1957). Trattato di diritto processuale civile. (Vol. I). Turín: UTET.

Rubio Correa, Marcial (2008). El Título Preliminar del Código Civil. Décima edición. Lima: Fondo Editorial de la Pontificia Universidad Católica del Perú.

Saredo, Giuseppe (1873). Istituzioni di procedura civile. Florencia: Pellas Editore. 
Sassani, Bruno (1989). Interesse ad agire [voz]. (Vol. XVII), de Enciclopedia giuridica. Roma: Istituto della Enciclopedia Italiana.

Satta, Salvatore (1954). "Interesse ad agire e legittimazione." I/ Foro italiano, 77(8), p. 169-178.

Schönke, Adolfo (1948). "Il bisogno di tutela giuridica (un concetto giusprocessualistico fondamentale)." Rivista di diritto processuale. Parte I, p. 132-152.
Véscovi, Enrique (1972). "La falta de acción en el proceso." Revista de la Facultad de Derecho de México, (85-86), p. 247-253.

Vicente y Caravantes, José de (1856). Tratado histórico, crítico filosófico de los procedimientos judiciales en materia civil según la nueva Ley de Enjuiciamiento. Madrid: Imprenta de Gaspar y Roig.

Zanzucchi, Marco Tullio (1947). Diritto processuale civile. (Vol. I). Milán: Giuffrè. 